\title{
A Clinical Classification of Hereditary Ataxias
}

\author{
A. Barbeau', M. Sadibelouiz ${ }^{1,2}$, A. Sadibelouiz ${ }^{1,2}$ and M. Roy ${ }^{1}$
}

\begin{abstract}
We present a working and flexible classification of inherited ataxic syndromes based on the use of simple tools available to every clinician: a good history (particularly pinpointing the age of onset, the rate of progression and the mode of inheritance) and a neurological examination (identifying the presence of ataxia, deep tendon reflexes in the knee, optic nerve, retinal and/or 8th nerve signs). This classification is easily coded for computer translation on any personal computer. The place occupied by a given disorder may, by contiguity, give a clue to its pathophysiology.
\end{abstract}

RÉSUMÉ: Nous présentons une classification de travail simple et flexible des syndromes ataxiques héréditaires qui n'emploie que les outils disponibles à tout clinicien: une bonne anamnèse (délimitant particulièrement l'âge de début, le mode de transmission héréditaire et la progression de la maladie) et un examen neurologique (incluant la vérification de la présence d 'une ataxie, des réflexes ostéotendineux aux genoux, des signes oculaires, rétiniens, auditifs ou vestibulaires). Cette classification a l'avantage de pouvoir étre facilement codée pour usage sur ordinateur personnel. La place assignée à un désordre en particulier peut servir d'indice sur sa pathophysiologie.

Can. J. Neurol. Sci. 1984; 11:501-505

In 1982, as a pilot study, we proposed a tentative classification of recessive ataxias and reviewed the major problems faced by previous authors in attempting to present a coherent nosography of the inherited ataxias (Barbeau, 1982). The difficulties are much worse for the disorders inherited as autosomal dominants, because in these entities the variability of expression appears to be maximal (for example see study of MachadoJoseph disease in this issue). It has been said that each neurologist who has written about the ataxias has proposed his own classification. Although many have been of some use, most schemes usually fall within one of two extremes: 1) too simple, and therefore lacking in precision, with "lumping" of different entities being a major obstacle to proper biochemical research; 2) too complex, and therefore impossible to use for all but the experts. Sometimes a tendancy to "splitting" marks the latter classifications.

\section{MEthodology}

In thinking about such a classification, it soon became evident to us that a certain number of basic criteria were essential. Because the classification is to be used during life, without the benefit of neuropathological examination, its first requirement is "to be clinician friendly", i.e. to be such that it can be used in any physician's office, without special equipment. The second requirement, based on the remembered frustrations of schemes which had to be redrawn every time a new syndrome was described, is flexibility. The inclusion of a new entity should be done without having to re-number every previous case registered. Similarly, the removal of a previously differentiated disease, should not disrupt the neatness of the classification. Finally, in this "age of the computer", the proposed classification should be easily coded, computerized and stored, preferably with the help of accessible programs and on commonly used personal computers. We present a classification which meets the three criteria.

The proposed nosology is presented in sequential fashion, following the natural order of questions asked by a clinician (Table 1). First: is the case under study hereditary or non hereditary? If hereditary, is the pattern observed in the family autosomal dominant, autosomal recessive or sex-linked recessive? Once the genetic mode has been established, the next question concerns the progression of the disease, a fact which can easily be elicited from the history; three main patterns are seen: non progressive, intermittent or progressive ataxia. In each class what is then the age of onset of the very first abnormal symptom,

From the Clinical Research Institute of Montreal (1), and the Department of Neurology, University of Alger, Algeria (2).

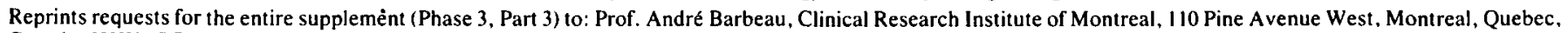
Canada, H2W IR7 
Table 1: Overall Scheme of Classification

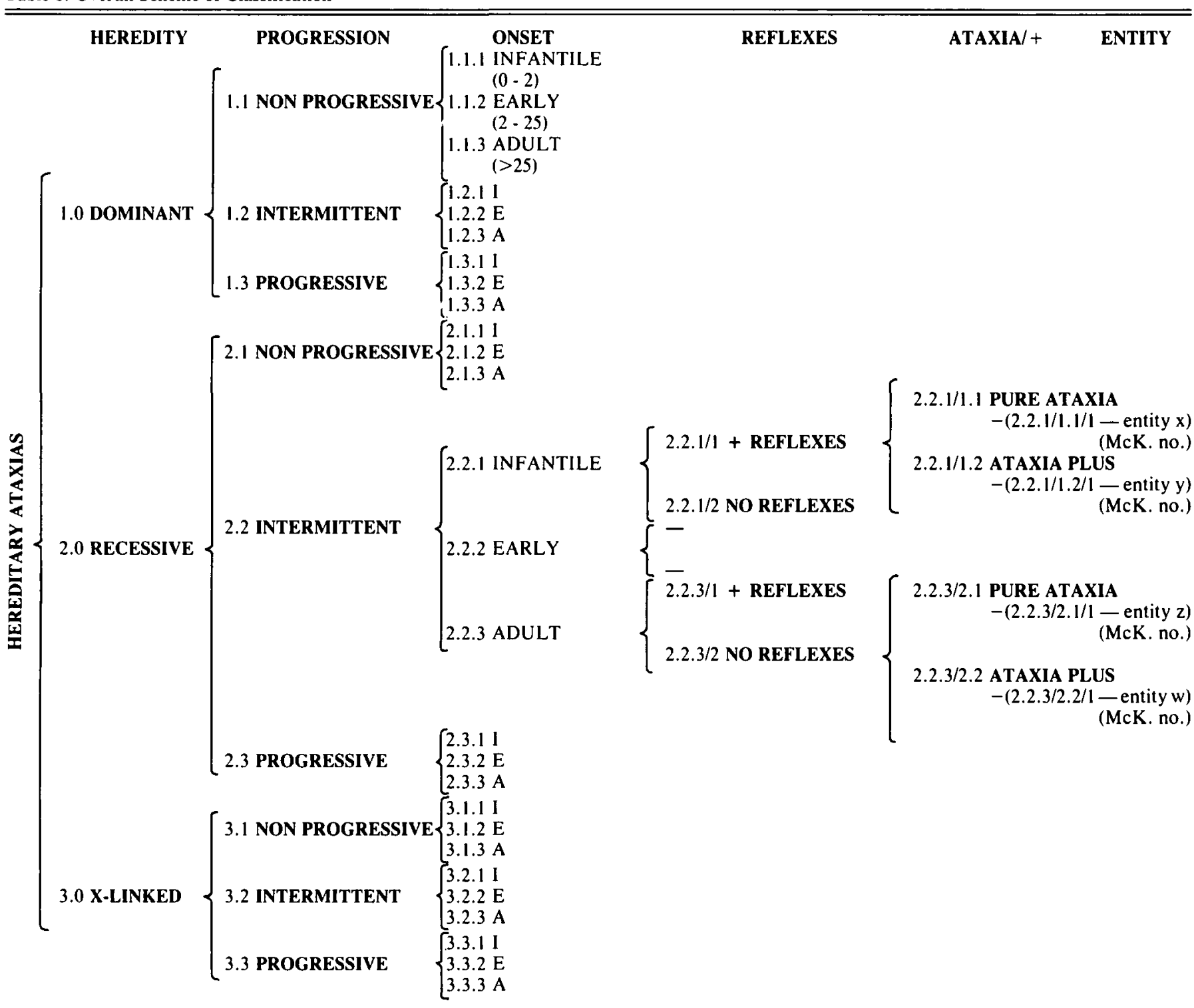

and particularly of the incoordination? Three broad categories have been adopted for this study: infantile (onset from birth to age two), early (onset from age two to twenty five), adult (here defined as onset after the age of 25). One recognizes that strict boundaries are almost never possible in medicine, particularly since recall of onset may be blurred in individual memories. This is the reason for wide ranges rather than more finite periods such as infancy, childhood, and adolescence. Moreover, our experience has been that the pathophysiology of different entities within these broad categories tends to be similar.

Further clinical considerations enter at this point: for example, what is the state of deep tendon reflexes? To standardize results and because it is the most reproducible and best known reflex, we have chosen the knee jerk as our basic criterion. The knee jerk can be hyper- or normo-active (called here + reflexes) or it can be markedly hypo-active or even areflexic (called here no reflexes). This simple test usually permits a delineation of most clinical syndromes encountered, particularly differentiating spastic entities from ganglioneuropathies.

Unfortunately, patients do not present with pure clinical tableaux. The principal symptom guiding our selection should by definition be ataxia, i.e.: incoordination of gait and limbs. However, as previously noted, optic atrophy, retinal and eight nerve changes are frequently seen in the ataxias. Their presence usually signals the existence of a more widespread disorder or of a fairly advanced stage of the disease.In the present study this occurence will also be used to further discriminate between many entities previously delineated:

In a first sub-type (called here "pure ataxia"), incoordination is the principal component and is not accompanied by eye (optic nerve or retinal) or ear (8th nerve) symptoms. (Electrophysiological tests are not used for this classification).

The second sub-type (called here "ataxia plus" includes incoordination which is accompanied by eye or ear symptoms. 
Although many more sub-classifications could be proposed based on other symptoms or signs, we have found that there is no need to further complicate the proposed scheme at this stage. Subscript letters can be used, when needed, to identify new or still undefined entities, or unusual variants which await clarification.

Definitions for the principal criteria are given in Table 2. They should be well studied for a clear understanding of the classification scheme presented. In Table 1 is also illustrated the coding procedure for the various categories. This numbering system has the advantage of being simple, sequential and easily converted to computer files. Each disease receives an individual code which automatically introduces it in its proper place within the scheme. To facilitate cross indexing and list the best references, we have added (in brackets) the number for that disease given in the 6th edition of McKusick's 'Mendelian Inheritance in Man' (1983), when available.

\section{RESUlts AND Discussion}

The classification of hereditary ataxias based on this scheme is listed in Table 3, and illustrated by two examples:

Friedreich's disease is given the code " $2.3 .2 / 2.1 / 2$ " which translates into "an autosomal recessive ataxia, of a progressive nature, early onset, diminished or absent knee jerks, without major involvement of other systems within the brain". In the same category are Bassen-Kornzweig's disease and the slow progression form of Friedreich, called Acadian Ataxia, with or without neurogenic atrophy. It is noteworthy that these diseases have very similar pathologies and pathophysiologies, although from different biochemical etiologies.

As further example Machado-Joseph disease is given the code "1.3.2/1.2/2d" which translates into "an autosomal dominant ataxia, of progressive nature, of early or adult onset /dominant disorders can start in both categories within the same kindred/ with hyper- or normo-active knee jerks". This disorder also involves more than the spino-cerebellar or cerebellar systems and is thus one of the "Ataxic multi-system degenerations", which include olivo-ponto-cerebellar atrophies (OPCA), with

Table 2: Definitions

\begin{tabular}{|c|c|c|}
\hline $\begin{array}{l}\text { 1. ONSET } \\
\text { AGES }\end{array}$ & $\begin{array}{l}\text { INFANTILE } \\
\text { EARLY } \\
\text { ADULT }\end{array}$ & $\begin{array}{l}0-2 \text { years } \\
2-25 \text { years } \\
>25 \text { years }\end{array}$ \\
\hline 2. REFLEXES & $\begin{array}{l}\text { (a) "+ REFLEXES" } \\
\text { (b) "NO REFLEXES" }\end{array}$ & $\begin{array}{l}\text { Knee-jerk normal or } \\
\text { increased } \\
\text { Knee-jerk decreased or } \\
\text { absent }\end{array}$ \\
\hline 3. ATAXIA & (a) "PURE ATAXIA" & $\begin{array}{l}\text { Neurological syndrome with } \\
\text { predominant incoordination } \\
\text { (spino-cerebellar or cerebellar) } \\
\text { with no involvement of other } \\
\text { CNS systems }\end{array}$ \\
\hline & (b) "ATAXIA PLUS" & $\begin{array}{l}\text { Incoordination (spino-cere- } \\
\text { bellar or cerebellar) + other } \\
\text { system involvement in CNS }\end{array}$ \\
\hline 4. N.Y.K. & \multicolumn{2}{|c|}{ Not yet known or classified } \\
\hline 5. (McK. no.) & \multicolumn{2}{|c|}{$\begin{array}{l}\text { Number assigned to disease in 6th edition of McKusick's } \\
\text { "Mendelian Inheritance in Man" (1983) }\end{array}$} \\
\hline
\end{tabular}

or without retinal or oculomotor involvement, and dentatorubro-pallido-luysian atrophies.

\section{Conclusion}

To date 57 individualized ataxic syndromes have been identified, coded and classified using the proposed scheme (Table 3). The list is not exhaustive and can be added to as new entities are better defined. One of the principal uses of this classification, as we see it, will be to offer some clues as to the pathophysiology of given disorders. Indeed, diseases with similar etiologies tend to be grouped in their overall clinical spectrum of symptoms and signs. For example, in recessive disorders, most of the spastic ataxias with multi-system involvement are in category $2.3 .1 / 1.2$; most of the hereditary metabolic enzyme deficiencies in category 2.2.1/1.1; most of the late onset lysosomal disorders 2.3.2/1.2. Similarly, it is striking that the ganglioneuropathies are almost all in group 2.3.2/2.1.

The proposal of this new scheme is not final. It is evident that if the classification meets with general approval, the next step will be to define the other criteria necessary for each of the entities enumerated and to provide a list of the biochemical tests useful to establish and confirm the diagnosis. For example 2.3.2/2.2 leads to Refsum's disease. The following should be added to the previously used criteria which provided this number: skin changes, retinitis pigmentosa, deafness and the determination of phytanic acid. Although obvious to the specialist, such signs and biochemical tests may not have been thought of by the general practitioner not used to hereditary ataxias. However, he should have been able to deduce that this entity is an autosomal recessive disease of progressive nature and early onset (2.3.2), that it is accompanied by reduced or absent knee jerks, and that the ataxia is accompanied by skin changes (2.3.2/2.2). At this time, only one disease is listed under that category. The other criteria and biochemical tests would confirm the diagnosis.

Table 3: A clinical classification of hereditary ataxias

\subsection{AUTOSOMAL DOMINANT DISORDERS}

1.1 NON-PROGRESSIVE

1.1.1 Infantile onset: N.Y.K.

1.1.2 Early onset: N.Y.K.

1.1.3 Adult onset: N.Y.K.

1.2 INTERMITTENT

1.2.1 Infantile onset: N.Y.K.

1.2.2 Early onset:

1.2.2/1: + reflexes

1.2.2/1.1: pure ataxia

$-(1.2 .2 / 1.1 / 1)$ : familial intermittent cerebellar ataxia (Hill-

Sherman) (10850)

1.2.2/1.2: ataxia plus:

1.2.2/2: no reflexes: N.Y.K. N.Y.K.

1.2.3 Adult onset

1.2.3/1: + reflexes

1.2.3/1.1: pure ataxia

$-(1.2 .3 / 1.1 / 1)$ : vestibulo-cerebellar periodic ataxia (FarmerMustian)(10850)(*possibly same as: $1.2 .2 / 1.1 / 1)$

1.2.3/1.2: ataxia plus: N.Y.K.

1.2.3/2: no reflexes: N.Y.K. 
1.3 PROGRESSIVE

1.3.1 Infantile onset: N.Y.K.

1.3.2 Early onset:

1.3.2/1: + reflexes

1.3.2/1.1: pure ataxia

$-(1.3 .2 / 1.1 / 1)$ : late cortical cerebellar atrophy (Holmes) (11740)

1.3.2/1.2: ataxia plus

$-(1.3 .2 / 1.2 / 1)$ : dominant spastic ataxia (Ferguson-Critchley) (10860)

$-(1.3 .2 / 1.2 / 2):$ ataxic multisystem degenerations

(a) (Konigsmark I, IV, V) $(16440 ; 16460 ; 16470)$

(b) O.P.C.A. + retinal degeneration (16450)

(c) slow saccade O.P.C.A. (Wadia-Swami) (11735)

(d) Machado-Joseph disease (10915)

(e) ataxia with fasciculations (Singh-Sham) (10870)

(f) dentato-rubro-pallidoluysian atrophy

1.3.2/2: no reflexes

1.3.2/2.1: pure ataxia

$-(1.3 .2 / 2.1 / 1)$ : hypo-beta-lipoproteinemia (Mars) (14595)

1.3.2/2.2: ataxia plus $-(1.3 .2 / 2.2 / 1)$ : ataxic erythrokeratodermia (Barbeau-Giroux) (13319)

1.3.3 Adult onset: see early onset - dominant cases can start indifferently in early or adult periods within the same kindred

\subsection{AUTOSOMAL RECESSIVE DISORDERS}

\subsection{NON-PROGRESSIVE}

2.1.1 Infantile Onset:

2.1.1/1: + reflexes

2.1.1/1.1: pure ataxia

$-(2.1 .1 / 1.1 / 1)$ : congenital dysequilibrium syndrome (Sanner) (22405)

-(2.1.1/1.1/2): congenital cerebellar ataxia (Batten-Lamy)

$-(2.1 .1 / 1.1 / 3)$ : congenital cerebellar vermis agenesis (Joubert) (21330)

2.1.1/1.2: ataxia plus

$$
-(2.1 .1 / 1.2 / 1) \text { congenital ataxic diplegia }
$$
(Gustavson)

2.1.1/2: no reflexes: N.Y.K.

2.1.2 Early onset

2.1.2/1: + reflexes

2.1.2/1.1: pure ataxia: N.Y.K.

2.1.2/1.2: ataxia plus

$-(2.1 .2 / 1.2 / 1)$ : late infantile metachromatic leukodystrophy (25010)

2.1.2/2: no reflexes: N.Y.K.

2.1.3 Adult onset: N.Y.K.

2.2 INTERMITTENT

2.2.1 Infantile onset

2.2.1/1: + reflexes

2.2.1/1.1: pure ataxia

$-(2.2 .1 / 1.1 / 1)$ : citrullinemia (21570)

$-(2.2 .1 / 1.1 / 2)$ : arginino-succinic acidura (20790)

$-(2.2 .1 / 1.1 / 3)$ hyperornithinemia (25887)

$-(2.2 .1 / 1.1 / 4)$ : pyruvate carboxylase deficiency (26615)
$-(2.2 .1 / 1.1 / 5):$ Hartnup disease (23450)

$-(2.2 .1 / 1.1 / 6)$ : branched-chain ketonuria (maple syrup urine disease) (24860)

$-(2.2 .1 / 1.1 / 7):$ Leigh disease (25600)

2.2.1/1.2: ataxia plus: N.Y.K.

2.2.1/2: no reflexes: N.Y.K.

2.2.2 Early onset: N.Y.K.

2.2.3 Adult onset: N.Y.K.

2.3 PROGRESSIVE

2.3.1 Infantile onset

2.3.1/1: + reflexes

2.3.1/1.1: pure ataxia: N.Y.K.

2.3.1/1.2: ataxia plus

$-(2.3 .1 / 1.2 / 1)$ : ataxia-telangiectasia (Louis-Bar) (20890)

$-(2.3 .1 / 1.2 / 2)$ : Marinesco-Sjögren syndrome (24880)

$-(2.3 .1 / 1.2 / 3)$ : Sjögren-Larsson syndrome (27020)

$-(2.3 .1 / 1.2 / 4)$ : Behr syndrome (21000)

$-(2.3 .1 / 1.2 / 5)$ : Charlevoix-Saguenay syndrome

$-(2.3 .1 / 1.2 / 6):$ Troyer syndrome (27590)

$-(2.3 .1 / 1.2 / 7)$ : Cockayne syndrome (21640)

$-(2.3 .1 / 1.2 / 8)$ : Gillespie syndrome

$-(2.3 .1 / 1.2 / 9)$ : Hallgren syndrome

(2.3.1/1.2/10): Ataxia-deafness-mental retardation (ADR) syndrome

2.3.1/2: no reflexes: N.Y.K.

-(2.3.1/1.2/11): Richards-Rundle syndrome (24510)

2.3.2 Early onset

2.3.2/1: + reflexes

2.3.2/1.1: pure ataxia

$-(2.3 .2 / 1.1 / 1)$ : normo-reflexic recessive

2.3.2/1.2: ataxia plus ataxia (Harding)

$-(2.3 .2 / 1.2 / 1):$ Ramsey-Hunt syndrome (21340)

-(2.3.2/1.2/2): Xeroderma-Pigmentosum (27870)

$-(2.3 .2 / 1.2 / 3)$ : hereditary spastic ataxia (27050)

$-(2.3 .2 / 1.2 / 4)$ : Jeune syndrome

$-(2.3 .2 / 1.2 / 5)$ : later onset hexosaminidase deficiency

(a) a locus (Tay-Sacks) (27277)

(b) b locus (Sandhoff) (26880)

$-(2.3 .2 / 1.2 / 6)$ : later onset Nieman-Pick disease (25720)

$-(2.3 .2 / 1.2 / 7)$ : juvenile or chronic neuraminidase deficiency \pm B-

2.3.2/2: no reflexes galactosidase deficiency

2.3.2/2.1: pure ataxia

$-(2.3 .2 / 2.1 / 1)$ : Bassen-Kornzweig disease: a-beta-lipoproteinemia (20010)

$-(2.3 .2 / 2.1 / 2):$ Friedreich's disease (22930) (a) Friedreich's disease with slow progression (Acadian type)

(b) Friedreich's disease with neurogenic atrophy (Van Bogaert type) 
2.3.2/2.2: ataxia plus

$-(2.3 .2 / 2.2 / 1)$ : Refsum disease: phytanic acid storage disease (26650)

2.3.3 Adult onset

2.3.3/1: + reflexes

2.3.3/1.1: pure ataxia

$-(2.3 .3 / 1.1 / 1)$ : O.P.C.A. - Type II

2.3.3/1.2: ataxia plus

(Finkler-Winkler) (25830)

$-(2.3 .3 / 1.2 / 1)$ : cerebro-tendinous xanthomatosis (cerebral cholesterinosis) (21370)

$-(2.3 .3 / 1.2 / 2):$ GDH deficient multisystem degeneration (Plaitakis)

$-(2.3 .3 / 1.2 / 3)$ : lateronset metachromatic

2.3.3/2: no reflexes leukodystrophy (25020)

2.3.3/2.1: pure ataxia

$-(2.3 .3 / 2.1 / 1): \gamma$-glutamyl-cysteine synthetase deficiency (Richards) (23045)

2.3.3/2.2: ataxia plus: N.Y.K

\section{ACKNOWLEDGEMENTS}

The authors would like to thank Miss S. Paris, R.N. for record keeping and Mrs. Nicole Guay-Poirier for typing the manuscript. These studies were supported by a grant from " $L$ 'Association Canadienne de l'Ataxie de Friedreich". The classification presented is based on a study of nearly 600 hereditary ataxia cases seen in the Province of Quebec over the last 10 years.

\section{REFERENCES}

Barbeau, A (1982) A tentative classification of recessively inherited ataxias. Can J Neurological Sci. 9: 95-98.

McKusick, VA (1983) Mendelian inheritance in man. 6th edition, The Johns Hopkins University Press, Baltimore. 